\title{
The effect of biventricular pacing on cardiac function after weaning from cardiopulmonary bypass in patients with reduced left ventricular function: A pressure-volume loop analysis
}

\author{
Thorsten Hanke, MD, ${ }^{a}$ Martin Misfeld, MD, PhD, ${ }^{\text {a }}$ Matthias Heringlake, MD, ${ }^{\mathrm{b}}$ Jan J. Schreuder, MD, ${ }^{\mathrm{d}}$ \\ Uwe K. H. Wiegand, MD, ${ }^{c}$ and Frank Eberhardt, MD $^{\mathrm{c}}$
}

\begin{abstract}
Objective: Patients with severely reduced left ventricular function undergoing coronary artery bypass grafting have increased complication rates. We hypothesized that temporary postoperative atrial synchronous biventricular pacing would improve left ventricular function after cardiopulmonary bypass.
\end{abstract}

\begin{abstract}
Methods: A left ventricular pressure-volume catheter was placed in 21 patients undergoing coronary artery bypass grafting (ejection fraction $29 \% \pm 5 \%$ ). Pressure-volume loops were obtained after weaning from cardiopulmonary bypass with atrial synchronous biventricular, left ventricular, and right ventricular outflow tract pacing and atrial-only stimulation at 90 beats/min.
\end{abstract}

\begin{abstract}
Results: Steady-state systolic and preload-independent parameters were superior for atrial synchronous biventricular and left ventricular pacing and atrial-only pacing relative to atrial synchronous right ventricular outflow tract pacing $(P<.05)$. Diastolic parameters, excepting maximum negative rate of left ventricular pressure change, were unaffected. No significant differences were observed between atrial synchronous biventricular and left ventricular pacing and atrial-only pacing. Systolic dyssynchrony was significantly lower for atrial synchronous biventricular pacing $(21 \% \pm 5 \%)$, atrial synchronous left ventricular pacing $(20 \% \pm 6 \%)$, and atrial-only pacing $(20 \% \pm 6 \%)$ versus atrial synchronous right ventricular outflow tract pacing $(25 \%$ $\pm 7 \%, P<.05)$. Atrioventricular interval during atrial-only stimulation was positively correlated with difference in stroke work between atrial synchronous biventricular pacing and atrial-only pacing $\left(\mathrm{r}^{2}=0.78\right.$, $P>.001)$.
\end{abstract}

Conclusion: Postoperative atrial synchronous biventricular and left ventricular pacing and atrial-only stimulation significantly improve systolic function relative to atrial synchronous right ventricular outflow tract pacing. If atrioventricular conduction is prolonged, atrial synchronous biventricular pacing is preferable to atrial-only pacing.

Patients with severely reduced left ventricular (LV) function undergoing coronary artery bypass grafting $(\mathrm{CABG})$ have increased perioperative complication rates. ${ }^{1}$ These patients require more inotropic and intra-aortic balloon support and have prolonged stays on intensive care units relative to patients with normal LV function. About $9 \%$ of patients undergoing $\mathrm{CABG}$ require pacing in the postoperative period, usually for transient high-grade atrioventricular (AV) block or sinus bradycardia, a figure that increases with higher age and reduced LV function. ${ }^{2}$ Increasing the heart rate may also improve cardiac output if force-fre-

From the Department of Cardiac and Thoracic Vascular Surgery, ${ }^{\mathrm{a}}$ the Department of Anesthesiology, ${ }^{\mathrm{b}}$ Medical Clinic II, ${ }^{\mathrm{c}}$ University of Lübeck, Lübeck, Germany; and the Department of Cardiac Surgery, San Raffaele Hospital, ${ }^{\mathrm{d}}$ Milan, Italy.

T.H. and M.M. contributed equally to the article.

Disclosures: J.J.S. serves as a consultant for CD Leycom, Zoetermeer, The Netherlands. Received for publication Oct 22, 2008; revisions received Dec 31, 2008; accepted for publication Feb 1, 2009.

Address for reprints: Frank Eberhardt, MD, Evangelisches Krankenhaus Koeln-Kalk, Buchforststrasse 2, 51103 Köln, Germany (E-mail: eberhardt@evkk.de).

J Thorac Cardiovasc Surg 2009;138:148-56

$0022-5223 / \$ 36.00$

Copyright (C) 2009 by The American Association for Thoracic Surgery

doi:10.1016/j.jtcvs.2009.02.010 quency relationships are maintained. ${ }^{3}$ Moreover, postoperative pacing may be beneficial to suppress postoperative atrial fibrillation, as has been shown for overdrive atrial-only pacing (AAI). ${ }^{4}$ When $\mathrm{AV}$ pacing is required for $\mathrm{AV}$ conduction abnormalities, right ventricular (RV) apical pacing may acutely give rise to LV dysfunction, as shown by several pressure-volume (PV) loop studies particularly in patients with reduced LV function. ${ }^{5-7}$ In contrast, atrial synchronous (DDD) biventricular (BIV) pacing represents an effective therapeutic modality that acutely improves LV function in the patient with heart failure who has a wide QRS complex and an ejection fraction less than $35 \%{ }^{8}$ Limited and inhomogeneous data are available for DDD-BIV pacing in cardiac surgical patients with severely reduced LV function. ${ }^{9-12}$ PV loops offer the potential to evaluate intrinsic LV function at high spatial and temporal resolution and independently of loading conditions. Moreover, PV analysis provides information on mechanical dyssynchrony and the mechanical efficiency of cardiac contraction. ${ }^{8,13}$ This study was designed to determine the effects of DDD-BIV or DDD$\mathrm{LV}$ on LV function relative to standard pacing modes in a homogeneous group of patients with severely reduced LV function undergoing $\mathrm{CABG}$. 


$$
\begin{array}{ll}
\text { Abbreviations and Acronyms } \\
\begin{aligned}
\mathrm{AAI} & =\text { atrial-only pacing } \\
\mathrm{AV} & =\text { atrioventricular } \\
\mathrm{BIV} & =\text { biventricular } \\
\mathrm{CABG} & =\text { coronary artery bypass grafting } \\
\mathrm{CPB} & =\text { cardiopulmonary bypass } \\
\mathrm{DDD} & =\text { atrial synchronous pacing } \\
\mathrm{dP} / \mathrm{dt}_{\max } & =\text { maximum rate of left ventricular } \\
& \text { pressure change } \\
\mathrm{LV} & =\text { left ventricular } \\
\mathrm{PV} & =\text { pressure-volume } \\
\mathrm{RV} & =\text { right ventricular } \\
\mathrm{RVOT} & =\text { right ventricular outflow tract }
\end{aligned}
\end{array}
$$

\section{MATERIALS AND METHODS Patients}

Twenty-seven patients undergoing CABG between August 2004 and December 2006 with preoperative sinus rhythm, LV ejection fraction less than $35 \%$ on ventriculography, and a QRS width less than $120 \mathrm{~ms}$ were included in the study. Exclusion criteria were preoperative atrial fibrillation, emergency surgery, preoperative hemodynamic instability, and concomitant valve or aortic surgery. Patients with moderate to severe mitral regurgitation necessitating restrictive mitral valve annuloplasty were also excluded. The study protocol was approved by the institutional review board, and all patients gave written, informed consent. Three patients were excluded for failure to place the PV catheter, 1 patient was excluded for persistent atrial fibrillation, and 2 patients were excluded for severe hemodynamic instability at the time of weaning from cardiopulmonary bypass (CPB). Preoperative characteristics of the 21 patients included in the data analysis are shown in Table 1.

\section{Protocol}

Anesthesia was induced with etomidate and sufentanil and maintained with propofol, sufentanyl, and sevoflurane (before and after CPB). All patients received a pulmonary artery thermodilution catheter (Edwards Lifescience, Irvine, Calif). Fluid management was adjusted to maintain central venous pressure between 8 and $12 \mathrm{~mm} \mathrm{Hg}$ and pulmonary artery diastolic pressure between 15 and $18 \mathrm{~mm} \mathrm{Hg}$. Routine CABG was performed under moderate hypothermia with antegrade blood cardioplegia. Before weaning from $\mathrm{CPB}$, unipolar pacing wires (Streamline 6500; Medtronic Inc, Minneapolis, Minn) were sutured to the roof of the right atrium, the RV outflow tract (RVOT) in a midventricular paraseptal position, and the lateral free wall of the LV between the first diagonal and first marginal branch and connected to a dual-chamber external pacemaker (Pace 203H; Osypka, Rheinfelden-Herten, Germany), as described previously. ${ }^{14}$ The indifferent electrode was placed subxiphoidally. All patients were operated on by the same surgeon (M.M.), and care was taken to ensure that the pacing wires

\begin{tabular}{|c|c|}
\hline \multicolumn{2}{|l|}{ Preoperative characteristics } \\
\hline Age $(y$, mean $\pm S D)$ & $66 \pm 11$ \\
\hline Male sex (no.) & 17 \\
\hline \multicolumn{2}{|l|}{ New York Heart Association functional class (no.) } \\
\hline I & 1 \\
\hline II & 10 \\
\hline III & 9 \\
\hline IV & 1 \\
\hline \multicolumn{2}{|l|}{ Canadian Cardiovascular Society class (no.) } \\
\hline I & 8 \\
\hline II & 4 \\
\hline III & 3 \\
\hline IV & 6 \\
\hline Previous coronary artery bypass grafting (no.) & 1 \\
\hline Ejection fraction $(\%$, mean $\pm \mathrm{SD})$ & $29 \% \pm 6 \%$ \\
\hline QRS width $(\mathrm{ms}$, mean $\pm \mathrm{SD})$ & $98 \pm 17$ \\
\hline PQ interval $(\mathrm{ms}$, mean $\pm \mathrm{SD})$ & $163 \pm 30$ \\
\hline \multicolumn{2}{|l|}{ Preoperative medication (no.) } \\
\hline Aspirin & 16 \\
\hline$\beta$-Blocker & 20 \\
\hline $\begin{array}{l}\text { Angiotensin-converting enzyme inhibitor } \\
\text { or angiotensin type } 1 \text { antagonist }\end{array}$ & 19 \\
\hline Furosemide & 12 \\
\hline Spironolactone & 9 \\
\hline Statins & 20 \\
\hline Amiodarone & 2 \\
\hline Digitalis & 3 \\
\hline \multicolumn{2}{|l|}{ Intraoperative data } \\
\hline Aortic crossclamp time (min, mean $\pm \mathrm{SD})$ & $75 \pm 34$ \\
\hline Cardiopulmonary bypass time (min, mean $\pm \mathrm{SD}$ ) & $100 \pm 40$ \\
\hline Veins used (mean $\pm \mathrm{SD})$ & $2.1 \pm 1.3$ \\
\hline Left internal thoracic graft (no.) & 20 \\
\hline Second arterial graft (no.) & 4 \\
\hline Third arterial graft (no.) & 1 \\
\hline $\begin{array}{l}\text { Left ventricular assist device or intra-aortic } \\
\text { balloon pump (no.) }\end{array}$ & 2 \\
\hline $\begin{array}{l}\text { Intraoperative } \mathrm{PQ} \text { interval during } \mathrm{AAI} \text { at } 90 \\
\text { beats/min }(\mathrm{ms}, \text { mean } \pm \mathrm{SD})\end{array}$ & $205 \pm 37$ \\
\hline Intraoperative $\mathrm{PQ}$ interval $(\mathrm{ms}$, mean $\pm \mathrm{SD})$ & $173 \pm 33$ \\
\hline Intraoperative QRS width (ms, mean $\pm \mathrm{SD}$ ) & $104 \pm 20$ \\
\hline
\end{tabular}
were placed in standardized positions. Weaning from CPB was accomplished in standard fashion. Enoximone $(1 \mu \mathrm{g} /[\mathrm{kg} \cdot \mathrm{min}])$ was given to all patients and adjusted to a maximum dose of $4 \mu \mathrm{g} /[\mathrm{kg} \cdot 8729 ; \mathrm{min}]$ to achieve mixed venous oxygen saturation higher than $75 \%$ and a cardiac index of more than $2.2 \mathrm{~L} /\left(\mathrm{min} \cdot 8729 ; \mathrm{m}^{2}\right)$. If these hemodynamic goals were not accomplished despite raised filling pressures (central venous pressure $>15 \mathrm{~mm}$ $\mathrm{Hg}$; pulmonary artery diastolic pressure $>18 \mathrm{~mm} \mathrm{Hg}$ ), dobutamine in incremental doses up to $10 \mu \mathrm{g} /(\mathrm{kg} \cdot 8729$; $\min )$ was used. If necessary, norepinephrine was infused to achieve a mean arterial pressure greater than 65 $\mathrm{mm} \mathrm{Hg}$. After weaning from CPB, a 7F combined PV catheter (CD Leycom, Zoetermeer, The Netherlands) was placed in the LV through the pulmonary
TABLE 1. Preoperative and intraoperative patient data $(\mathbf{n}=\mathbf{2 1})$

$A A I$, Atrial pacing and sensing with inhibited response.

vein. PV catheter position was verified by transesophageal echocardiography and inspection of segmental volume signals. The PV catheter was coupled to a cardiac function lab (Leycom CFL512; CD Leycom) that digitized PV signals at a sample rate of $250 \mathrm{~Hz}$. LV volume was calibrated by thermodilution cardiac output and hypertonic saline dilution. ${ }^{15}$ Measurements were performed 15 to 30 minutes after successful weaning from CPB during suspended ventilation with hemodynamic steady-state conditions at constant rates of inotropic support. Patients were paced at a constant rate of 90 beats/min or at least 10 beats above the intrinsic heart rate, analogous to the atrial pacing studies to prevent postoperative atrial fibrillation. ${ }^{4}$ Pacing modes were tested in random order according to a computer-generated randomization sheet. Between measurements, patients were paced by AAI at 90 beats/min as the baseline pacing mode. The $\mathrm{AV}$ interval was programmed to $120 \mathrm{~ms}$ to ensure true BIV capture. PV loops were obtained with DDD-BIV, DDD-LV, DDD-RVOT, and AAI for at least 30 seconds after changing the pacing modes. Sequences of at least 15 beats were recorded for further offline analysis. Sequences with arrhythmias were discarded, and the 

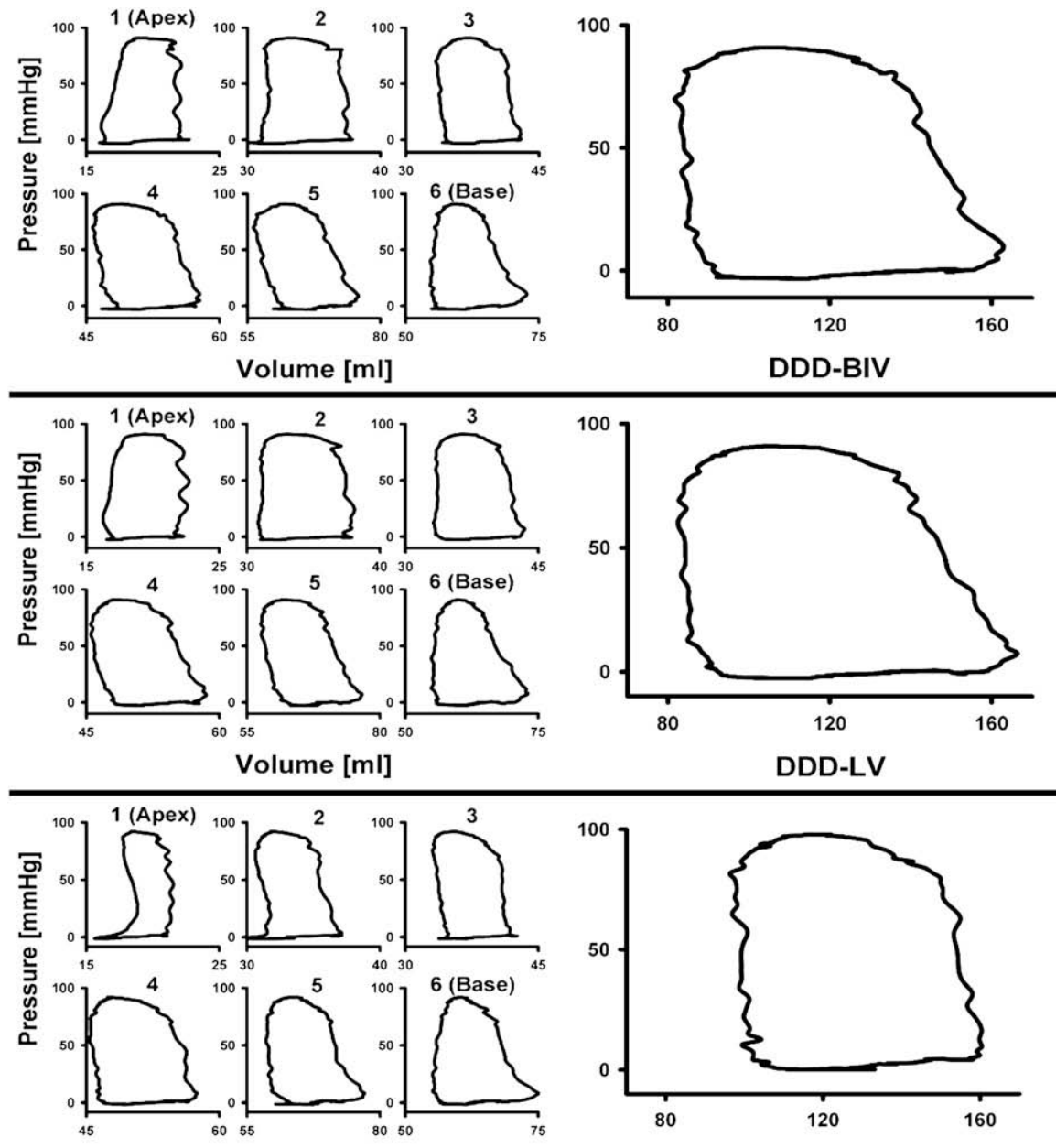

Volume $[\mathrm{ml}]$
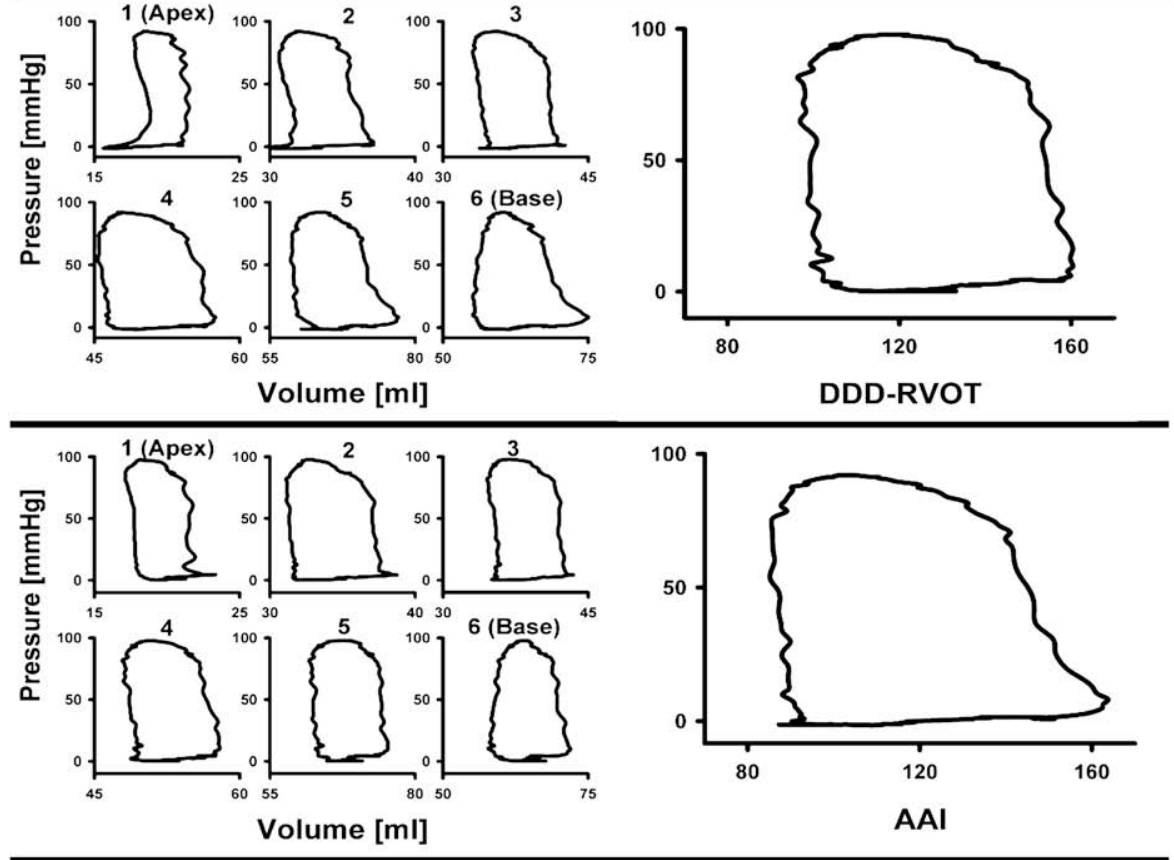

FIGURE 1. Segmental and global left ventricular pressure-volume loops during different pacing modes in representative patient. Segments of catheter are numbered from 1 (apex) to 6 (base) along longitudinal axis of catheter. Integrated volume of all segmental volumes constitutes total volume, which is represented in global pressure-volume loop. Apical segments are more distorted by right ventricular-based pacing (atrial synchronous right ventricular outflow tract pacing, $D D D-R V O T$ ) than by left ventricular-based pacing (atrial synchronous biventricular pacing, $D D D-B I V$, and atrial synchronous left ventricular pacing, $D D D-L V$ ) or by atrial-only pacing (AAI).

measurements were repeated. In 14 patients, baseline measurements were also recorded during sinus rhythm and compared with AAI at 90 beats/ min to determine force-frequency relationships.

\section{Data Analysis}

Data were analyzed offline with commercially available software (Conduct NT; CD Leycom). Global cardiac function was quantified by LV end-diastolic and end-systolic pressures, LV end-diastolic and end-systolic volumes, the maximum rates of positive and negative LV pressure change $\left(+\mathrm{dP} / \mathrm{dt}_{\max }\right.$ and $\left.-\mathrm{dP} / \mathrm{dt}_{\max }\right)$, stroke volume, cardiac index, stroke work, peak ejection rate during systole, peak filling rate during diastole, and the time constant of isovolumetric relaxation. The following preload independent contractility indices were measured during vena caval occlusion until a nadir of the LV volume was obtained with each pacing mode: the slope of 
TABLE 2. Hemodynamic data for different pacing modes

\begin{tabular}{|c|c|c|c|c|}
\hline & DDD-BIV & DDD-LV & DDD-RVOT & AAI \\
\hline Heart rate (beats/min) & $94 \pm 9$ & $94 \pm 9$ & $94 \pm 8$ & $94 \pm 9$ \\
\hline Stroke volume $(\mathrm{mL})$ & $71 \pm 16$ & $71 \pm 18$ & $67 \pm 16$ & $69 \pm 17$ \\
\hline Ejection fraction $(\%)$ & $36 \% \pm 10 \%$ & $36 \% \pm 11 \%$ & $34 \% \pm 10 \%$ & $35 \% \pm 11 \%$ \\
\hline Cardiac index $\left(\mathrm{L} /\left[\mathrm{min} \cdot \mathrm{m}^{2}\right]\right)$ & $2.72 \pm 2.36^{*}$ & $2.67 \pm 0.71 \dagger$ & $2.45 \pm 0.70$ & $2.66 \pm 2.38 \dagger$ \\
\hline Stroke work (mm Hg/mL) & $4197 \pm 1259 \dagger$ & $3974 \pm 1251$ & $3673 \pm 1369$ & $4129 \pm 1215$ \\
\hline$+\mathrm{dP} / \mathrm{dt}_{\max }(\mathrm{mm} \mathrm{Hg} / \mathrm{s})$ & $991 \pm 263 *$ & $1022 \pm 266^{*}$ & $841 \pm 236$ & $1033 \pm 228^{*}$ \\
\hline Peak ejection rate $(\mathrm{mL} / \mathrm{s})$ & $-515 \pm 173$ & $-528 \pm 261$ & $-537 \pm 235$ & $-552 \pm 250$ \\
\hline End-diastolic pressure $(\mathrm{mm} \mathrm{Hg})$ & $13.0 \pm 7.1$ & $11.7 \pm 6.0$ & $12.4 \pm 7.3$ & $11.8 \pm 6.9$ \\
\hline End-systolic pressure (mm Hg) & $81.4 \pm 20.5$ & $80.9 \pm 20.4$ & $78.8 \pm 19.0$ & $81.8 \pm 15.9$ \\
\hline End-diastolic volume (mL) & $165.0 \pm 41.6$ & $160.9 \pm 43.5$ & $162.8 \pm 39.6$ & $161.6 \pm 43.6$ \\
\hline End-systolic volume (mL) & $104.3 \pm 33.0$ & $101.1 \pm 35.4 \dagger$ & $106.2 \pm 33.5$ & $104.8 \pm 35.3$ \\
\hline$-\mathrm{dP} / \mathrm{dt}_{\max }(\mathrm{mm} \mathrm{Hg} / \mathrm{s})$ & $847 \pm 181 \dagger$ & $-851 \pm 183 \dagger$ & $-775 \pm 184$ & $-850 \pm 166 \dagger$ \\
\hline Time constant of isovolumetric relaxation (ms) & $34.3 \pm 9.5$ & $34.9 \pm 8.4$ & $35.7 \pm 7.9$ & $34.5 \pm 7.4$ \\
\hline Peak filling rate $(\mathrm{mL} / \mathrm{s})$ & $647 \pm 253$ & $683 \pm 301$ & $634 \pm 282$ & $623 \pm 245$ \\
\hline End-systolic elastance $(\mathrm{mm} \mathrm{Hg} / \mathrm{mL})$ & $0.87 \pm 0.24 \dagger$ & $0.88 \pm 0.30 \dagger$ & $0.79 \pm 0.22$ & $0.86 \pm 0.30 \dagger$ \\
\hline Arterial elastance $(\mathrm{mm} \mathrm{Hg} / \mathrm{mL})$ & $1.22 \pm 0.44$ & $1.21 \pm 0.44$ & $1.22 \pm 0.38$ & $1.25 \pm 0.43$ \\
\hline Ventriculoarterial coupling & $0.775 \pm 0.667 \dagger$ & $0.766 \pm 0.271 \dagger$ & $0.682 \pm 0.232$ & $0.746 \pm 0.423$ \\
\hline Preload recruitable stroke work $(\mathrm{mm} \mathrm{Hg})$ & $51.5 \pm 10.4 \dagger$ & $50.5 \pm 12.2 \dagger$ & $45.7 \pm 13.9$ & $52.7 \pm 14.3 \dagger$ \\
\hline$+\mathrm{dP} / \mathrm{dt}_{\max }-\mathrm{V}_{\mathrm{ed}}$ & $6.25 \pm 1.87^{*}$ & $6.73 \pm 2.25^{*}$ & $5.38 \pm 1.79$ & $6.77 \pm 2.02 *$ \\
\hline Pressure-volume area $(\mathrm{mm} \mathrm{Hg} / \mathrm{mL})$ & $6444 \pm 1735 \dagger$ & $6459 \pm 1935 \dagger$ & $5827 \pm 1673$ & $6313 \pm 1795$ \\
\hline Global cycle efficiency & $0.658 \pm 0.103$ & $0.633 \pm 0.139$ & $0.632 \pm 0.141$ & $0.672 \pm 0.136$ \\
\hline
\end{tabular}

All data are mean \pm SD. $D D D$, Atrial synchronous pacing; $B I V$, biventricular; $L V$, left ventricular; $R V O T$, right ventricular outflow tract; $A A I$, atrial pacing and sensing with inhibited response; $d P / d t_{\max }$, maximum rate of left ventricular pressure change; $+d P / d t_{\max }-V_{e d}$, slope of the relationship of $+\mathrm{dP} / \mathrm{dt} t_{\max }$ and end-systolic volume. *Significant difference versus atrial synchronous right ventricular outflow tract pacing, $P<.01$. $†$ Significant difference versus atrial synchronous right ventricular outflow tract pacing, $P<.05$.

the end-systolic PV relationship (the end-systolic elastance), the slope of stroke work against end-diastolic volume (the preload recruitable stroke work) and the slope of the relationship between $+\mathrm{dP} / \mathrm{dt}_{\max }$ and end-diastolic volume. Effective arterial elastance was calculated as end-systolic pressure divided by stroke volume. ${ }^{16}$ Ventriculoarterial coupling was defined as end-systolic elastance divided by arterial elastance ${ }^{17} \mathrm{PV}$ area was calculated as the change in LV pressure divided by the change in LV volume, resulting in an energetically ideal rectangular PV diagram. ${ }^{17}$ Global cycle efficiency, defined as stroke work divided by PV area, takes the distortions of the actual PV loop into account and is a measure of how much external energy is converted into mechanical energy. ${ }^{17} \mathrm{LV}$ dyssynchrony was determined from segmental volume signals. ${ }^{13}$ A segmental signal was considered to be dyssynchronous if its change was opposite to the simultaneous change in total LV volume. Segmental dyssynchrony was calculated as the percentage of time within the cardiac cycle that a segment was dyssynchronous. Total dyssynchrony was the average of segmental dyssynchrony in all segments. Systolic dyssynchrony was determined from $\mathrm{R}$ wave to $-\mathrm{dP} / \mathrm{dt}_{\max }$; diastolic dyssynchrony was determined from $-\mathrm{dP}^{\mathrm{d}} \mathrm{dt}_{\max }$ to $\mathrm{R}$ wave. Systolic dyssynchrony was subdivided into early systole from $\mathrm{R}$ wave to $+\mathrm{dP} / \mathrm{dt}_{\max }$ and late systole from $+\mathrm{dP} / \mathrm{dt}_{\max }$ to end-systolic volume. Diastolic dyssynchrony was subdivided into early diastole from end-systolic volume to peak flow rate and late diastole from peak flow rate to $\mathrm{R}$ wave.

\section{Statistical Analysis}

Statistical analysis was performed with SPSS for Windows version 12.0.1 (SPSS Inc, Chicago, Ill). Data are expressed as mean \pm SD. Hemodynamic parameters followed Gaussian distribution and were compared with 2-way analysis of variance for repeated measurements. The Tukey test with a $95 \%$ confidence interval was used for post hoc comparisons between pacing groups. Hemodynamic parameters during sinus rhythm and $\mathrm{AAI}$ at 90 beats/min were compared with the Wilcoxon test for matched pairs. Statistical relationships between selected preoperative and intraoperative parameters were tested with least squares linear regression.
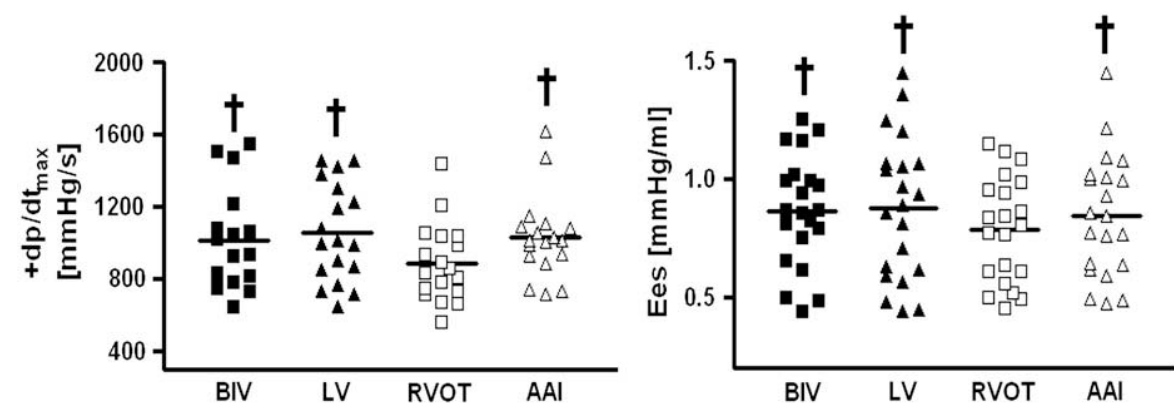

FIGURE 2. Individual patient data for maximum rate of positive left ventricular pressure change $\left(+d P / d t_{\max }\right)$ and end-systolic elastance $(E e s)$. Overall responses to atrial synchronous biventricular pacing $(D D D-B I V)$, atrial synchronous left ventricular pacing $(D D D-L V)$, and atrial-only pacing $(A A I)$ are superior to atrial synchronous right ventricular outflow tract pacing $(D D D-R V O T)$. Dagger indicates $P<.05$. Lines indicate mean values. 


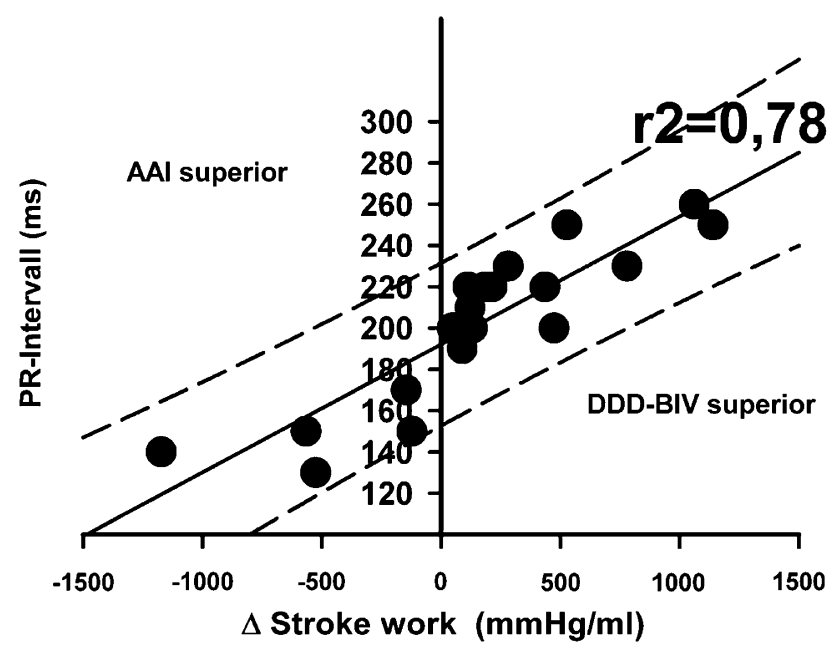

FIGURE 3. Regression diagram showing difference $(\Delta)$ in stroke work (value for atrial synchronous biventricular pacing $[D D D-B I V]$ minus value for atrial-only pacing $[A A I]$ ) plotted against PR interval during atrial-only pacing at 90 beats/min. Dotted lines represent $95 \%$ confidence interval. Patients with more stroke work in response to atrial-only pacing are plotted left of y-axis, whereas patients with higher stroke work in response to atrial synchronous biventricular pacing are plotted right of $y$-axis.

\section{RESULTS}

\section{Preoperative and Intraoperative Data}

Table 1 shows preoperative and intraoperative data for the 21 patients after weaning from CPB. All patients received standard medication for ischemic heart disease, including angiotensin-converting enzyme inhibitors, $\beta$-blockers, statins, and diuretics. Two patients required the implantation of an intra-aortic balloon pump after PV loops had been recorded because of high inotrope or vasopressor needs. Preoperative PQ interval was in the reference range and did not change from preoperative to intraoperative measurements. AAI at 90 beats/min led to a significant prolongation of PQ interval, from $173 \pm 33 \mathrm{~ms}$ to $205 \pm 37 \mathrm{~ms}(P<.01)$. QRS interval showed a moderate but significant prolongation, from $98 \pm 17 \mathrm{~ms}$ preoperatively to $104 \pm 20 \mathrm{~ms}$ intraoperatively $(P<.05)$. Phrenic nerve stimulation during DDD-LV or DDD-BIV was not observed.

\section{Hemodynamic Parameters}

Representative regional and global PV loops for each pacing mode in a single patient are shown in Figure 1. Hemodynamic data are summarized in Table 2 . The systolic variables of cardiac index, stroke work, and $+\mathrm{dP} / \mathrm{dt}_{\max }$, as well as the preload-independent variables of end-systolic elastance, preload recruitable stroke work, and $+\mathrm{dP} / \mathrm{dt}_{\max } \mathrm{di}-$ vided by end-diastolic volume, were significantly lower during DDD-RVOT than during DDD-BIV, DDD-LV, and AAI (Table 2, Figure 2). Because the arterial elastance remained stable between pacing modes, concurrent differences in ventriculoarterial coupling could be observed.
TABLE 3. Hemodynamic data for the 14 patients measured during sinus rhythm versus atrial pacing and sensing with inhibited response

\begin{tabular}{|c|c|c|}
\hline & Sinus rhythm & AAI \\
\hline Heart rate (beats/min) & $79 \pm 17$ & $95 \pm 10^{*}$ \\
\hline Stroke volume (mL) & $74 \pm 17$ & $70 \pm 17$ \\
\hline Ejection fraction $(\%)$ & $35.3 \% \pm 6.8 \%$ & $32.3 \% \pm 6.2 \% \dagger$ \\
\hline Cardiac index $\left(\mathrm{L} /\left[\mathrm{min} \cdot \mathrm{m}^{2}\right]\right)$ & $2.62 \pm 0.56$ & $3.02 \pm 0.83 \dagger$ \\
\hline Stroke work $(\mathrm{mm} \mathrm{Hg} / \mathrm{mL})$ & $4346 \pm 1503$ & $4447 \pm 1533$ \\
\hline$+\mathrm{dP} / \mathrm{dt}_{\max }(\mathrm{mm} \mathrm{Hg} / \mathrm{s})$ & $988 \pm 290$ & $1120 \pm 302 \dagger$ \\
\hline Peak ejection rate (mL/s) & $-557 \pm 211$ & $-611 \pm 230 \dagger$ \\
\hline End-diastolic pressure $(\mathrm{mm} \mathrm{Hg})$ & $12.6 \pm 5.8$ & $12.5 \pm 7.2$ \\
\hline End-systolic pressure (mm Hg) & $80.3 \pm 23.2$ & $82.9 \pm 15.7$ \\
\hline End-diastolic volume (mL) & $169.6 \pm 57.7$ & $169.0 \pm 59.3$ \\
\hline End-systolic volume (mL) & $105.7 \pm 44.3$ & $108.8 \pm 45.6$ \\
\hline 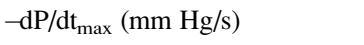 & $-818 \pm 235$ & $-900 \pm 185$ \\
\hline $\begin{array}{l}\text { Time constant of isovolumetric } \\
\text { relaxation }(\mathrm{ms})\end{array}$ & $35.2 \pm 7.3$ & $33.2 \pm 7.6$ \\
\hline Peak filling rate $(\mathrm{mL} / \mathrm{s})$ & $651 \pm 256$ & $657 \pm 240$ \\
\hline $\begin{array}{l}\text { End-systolic elastance } \\
\qquad(\mathrm{mm} \mathrm{Hg} / \mathrm{mL})\end{array}$ & $0.86 \pm 0.34$ & $0.82 \pm 0.28$ \\
\hline Arterial elastance $(\mathrm{mm} \mathrm{Hg} / \mathrm{mL})$ & $1.22 \pm 0.50$ & $1.32 \pm 0.44$ \\
\hline Ventriculoarterial coupling & $0.72 \pm 0.24$ & $0.63 \pm 0.17 \dagger$ \\
\hline $\begin{array}{l}\text { Preload recruitable stroke } \\
\text { work }(\mathrm{mm} \mathrm{Hg})\end{array}$ & $61.7 \pm 15.5$ & $51.5 \pm 10.3$ \\
\hline $\mathrm{dP} / \mathrm{dt}_{\max } /$ end-diastolic volume & $6.23 \pm 2.37$ & $6.87 \pm 2.13 \dagger$ \\
\hline $\begin{array}{l}\text { Pressure-volume area } \\
\qquad(\mathrm{mm} \mathrm{Hg} / \mathrm{mL})\end{array}$ & $6357 \pm 2112$ & $6324 \pm 2045$ \\
\hline Global cycle efficiency $(\%)$ & $0.675 \% \pm 0.051 \%$ & $0.698 \% \pm 0.065 \%$ \\
\hline
\end{tabular}

All data are mean \pm SD. $A A I$, Atrial pacing and sensing with inhibited response; $d P / d t_{\max }$, maximum rate of left ventricular pressure change. *Significant difference, $P<.01$. $†$ Significant difference, $P<.05$.

Diastolic variables, with the exception of $-\mathrm{dP} / \mathrm{dt}_{\max }$, were not different between DDD-RVOT and DDD-BIV, DDD$\mathrm{LV}$, and AAI. No significant differences for any variables could be determined between DDD-BIV, DDD-LV, and AAI. No significant correlation between any preoperative or intraoperative variable, with the exception of the intraoperative PR interval and stroke work, could be determined $\left(r^{2}=0.21, P=.05\right)$. Determination of differential values between stroke work during DDD-BIV and AAI and intraoperative PR interval, however, yielded a significant correlation with higher stroke work intervals $\left(\mathrm{r}^{2}=0.78, P<.001\right.$; Figure 3) during DDD-BIV with increasing PR intervals. Differential values for cardiac index showed similar results $\left(\mathrm{r}^{2}=0.43, P=.003\right)$. The 14 patients measured during sinus rhythm showed significant increases in cardiac index, $+\mathrm{dP} /$ $\mathrm{dt}_{\max }$, peak ejection rate, and $+\mathrm{dP} / \mathrm{dt}_{\max }$ divided by end-diastolic volume as a result of AAI pacing, whereas ejection fraction and ventriculoarterial coupling decreased significantly (Table 3 ). When only the patients with a sinus rate lower than 70 beats/min were analyzed, the significant increase in several systolic parameters remained significant in the AAI group, without any decrease of mechanical efficiency (Table 4). AAI led to a small but significant 
TABLE 4. Hemodynamic data for 6 patients in sinus rhythm at a rate lower than 70 beats/min versus atrial pacing and sensing with inhibited response

\begin{tabular}{lcc}
\hline & Sinus rhythm & AAI \\
\hline Heart rate (beats/min) & $64.3 \pm 2.8$ & $90 \pm 0^{*}$ \\
Stroke volume $(\mathrm{mL})$ & $77.7 \pm 14.3$ & $75.5 \pm 20.2$ \\
Ejection fraction $(\%)$ & $31.7 \% \pm 3.7 \%$ & $30.2 \% \pm 3.8 \%$ \\
Cardiac index $\left(\mathrm{L} /\left[\mathrm{min} \cdot \mathrm{m}^{2}\right]\right)$ & $2.55 \pm 0.27$ & $3.39 \pm 0.81 \dagger$ \\
Stroke work $(\mathrm{mm} \mathrm{Hg} / \mathrm{mL})$ & $4665 \pm 1779$ & $5101 \pm 1906$ \\
$+\mathrm{dP}_{\mathrm{ddt}}$ max $(\mathrm{mm} \mathrm{Hg} / \mathrm{s})$ & $932 \pm 339$ & $1145 \pm 399 \dagger$ \\
Peak ejection rate $(\mathrm{mL} / \mathrm{s})$ & $-549 \pm 282$ & $-579 \pm 294 \dagger$ \\
End-systolic elastance $(\mathrm{mm} \mathrm{Hg} / \mathrm{mL})$ & $0.65 \pm 0.36$ & $0.63 \pm 0.25$ \\
Ventriculoarterial coupling & $0.59 \pm 0.14$ & $0.53 \pm 0.08$ \\
Preload recruitable & $44.2 \pm 12.7$ & $47.8 \pm 9.3$ \\
$\quad$ stroke work $(\mathrm{mm} \mathrm{Hg})$ & &
\end{tabular}

$\overline{A A I \text {, Atrial pacing and sensing with inhibited response; } d P / d t_{\max } \text {, maximum rate of left }}$ ventricular pressure change. $*$ Significant difference, $P<.01$. $\dagger$ Significant difference, $P<.05$.

prolongation of the AV interval (Table 1) without affecting diastolic parameters (Table 3 ).

\section{Dyssynchrony Indices}

Total systolic dyssynchrony indices were significantly lower for DDD-BIV $(21 \% \pm 5 \%)$, DDD-LV $(20 \% \pm$ $6 \%)$, and AAI $(20 \% \pm 6 \%)$ than for DDD-RVOT $(25 \%$ $\pm 7 \%, P<.05)$. When systolic dyssynchrony was subdivided into early and late systolic dyssynchrony, these differences remained for early systole, whereas late systolic dyssynchrony was only significantly lower for AAI relative to DDD-RVOT (Figure 4). Diastolic dyssynchrony indices subdivided into isovolumetric relaxation and filling phases showed no significant differences between pacing modes. To determine the contribution of regional systolic dyssynchrony to total dyssynchrony, catheter segments where divided into apical, medial, and basal segments (Figure 5). Systolic dyssynchrony was significantly lower with DDD-BIV, DDD-LV, and AAI than with DDDRVOT in the apical segments but not the medial and basal segments.

\section{DISCUSSION}

Our results show superior systolic LV function during DDD-BIV, DDD-LV, and AAI pacing relative to standard DDD-RVOT pacing in patients with severely reduced LV function undergoing CABG. These results may be explained by differences in regional systolic dyssynchrony. Isovolumetric relaxation, as indicated by $-\mathrm{dP} / \mathrm{dt}_{\max }$, was also improved, whereas the filling phase remained largely unaffected. No overall significant differences were found between AAI and DDD-BIV or DDD-LV.

\section{BIV Pacing After Cardiac Surgery}

BIV pacing has become an established therapy for patients with heart failure with an ejection fraction less than

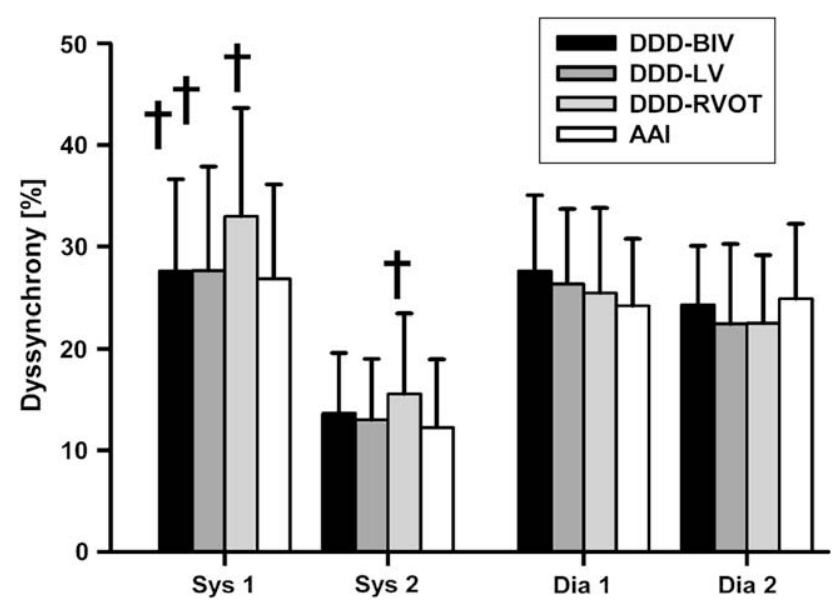

FIGURE 4. Alterations in dyssynchrony indices according to postoperative pacing mode. Systolic dyssynchrony is subdivided into early systole (Sys 1) and late systole (Sys 2). Diastole is subdivided into early (Dia 1) and late (Dia 2). Significant differences $(P<.05)$ versus atrial synchronous right ventricular outflow tract pacing (DDD-RVOT) are marked with daggers. $D D D-B I V$, Atrial synchronous biventricular pacing; $D D D-L V$, atrial synchronous left ventricular pacing; $A A I$, atrial-only pacing.

$35 \%$ and a QRS duration longer than $120 \mathrm{~ms} .{ }^{18}$ Acute improvements in several systolic parameters, such as ejection fraction, stroke work, and $+\mathrm{dP} / \mathrm{dt}_{\max }$ have been documented in several invasive studies. ${ }^{6,7,19}$ Echocardiographic studies have shown an acute improvement in systolic dyssynchrony after BIV pacing. ${ }^{20,21}$ These effects are maintained longterm with concomitant reverse remodeling after stimulation for 6 months, as shown by Steendijk and colleagues ${ }^{8}$ with serial PV loop measurements. Importantly, BIV pacing improves cardiac contractility without additional energy expenditure. $^{22}$ The potential to transfer these acute beneficial hemodynamic effects to cardiac surgical patients is intriguing. Several studies have evaluated BIV pacing after cardiac surgery, with mixed results ${ }^{9-12}$; however, these studies were small, with inhomogeneous populations that included patients with valve surgery and maintained LV function, and with measurements performed at variable time points after cardiac surgery. Acute hemodynamic results obtained in patients with chronic heart failure should not be expected to transfer straightforwardly to the patient undergoing CABG, because the hemodynamic situation is essentially different. After weaning from $\mathrm{CPB}$, hemodynamics must be evaluated in an open-chest situation with high levels of inotropes, rapid volume changes, and a variable degree of myocardial stunning after the use of CPB and cardioplegia. ${ }^{23}$ Placement of the LV pacing wire through the coronary sinus is limited by coronary sinus anatomy and results in electrical stimulation closer to the base of the heart than epicardial pacing at the free lateral wall. Although the RVOT is accessible through the endocardial approach, the vast majority of studies comparing RV and BIV pacing have used the 


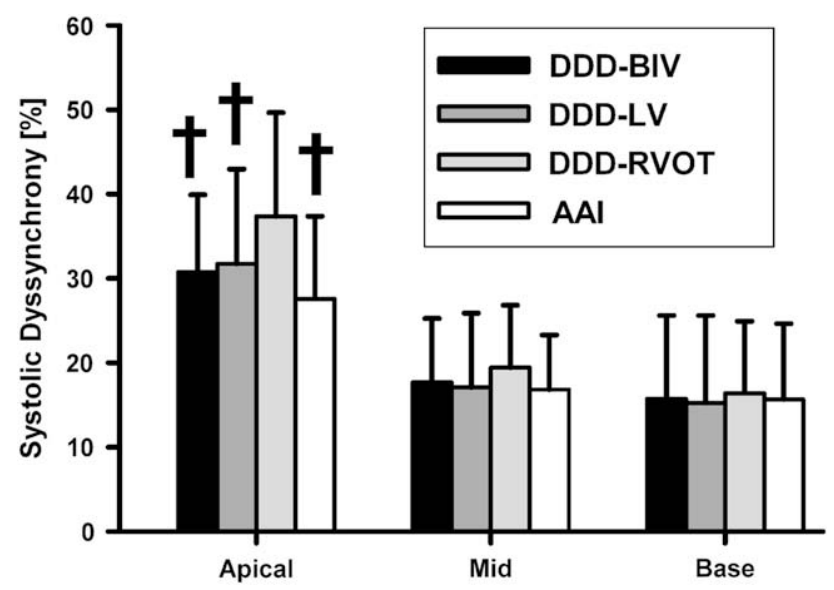

FIGURE 5. Alterations in regional systolic dyssynchrony according to pacing mode. Systolic dyssynchrony decreases from apex to base. Significant difference $(P<.0001)$ for apical versus mid and apical versus base for all pacing modes, mid versus base only significant $(P=.01)$ for atrial synchronous right ventricular outflow tract pacing (DDD-RVOT). Significant differences versus atrial synchronous right ventricular outflow tract are marked with daggers $(P<.05)$. DDD-BIV, Atrial synchronous biventricular pacing; $D D D-L V$, atrial synchronous left ventricular pacing; $A A I$, atrial-only pacing.

$\mathrm{RV}$ apical position. This is thus the first study to compare the hemodynamic effects of different stimulation modes on LV hemodynamics in a homogeneous population of patients undergoing $\mathrm{CABG}$ with ischemic cardiomyopathy.

\section{RVOT Pacing Versus BIV Pacing}

Systolic LV hemodynamic variables significantly improved during DDD-BIV, DDD-LV, and AAI relative to DDD-RVOT, whereas late diastolic relaxation and filling remained largely unaffected by the choice of pacing mode. In line with these findings, dyssynchrony indices were significantly improved during DDD-BIV, DDD-LV, and AAI relative to DDD-RVOT, whereas the diastolic dyssynchrony indices remained in the same range. Interestingly, systolic dyssynchrony was higher in the apical segments in all groups. After stratification according to the long heart axis, only the differences in apical dyssynchrony remained significant. This is also reflected in the apical distortion of regional PV loops during DDD-RVOT, which is a hallmark of inefficient conversion of external energy into mechanical energy (Figure 1). Lieberman and associates ${ }^{5}$ recorded regional PV loops during endocardial stimulation at apical, RVOT free wall, and RVOT septal pacing sites and showed the distortions of regional PV loops to correlate with the RV pacing site. Because we used an epicardial right midventricular paraseptal position for the RV lead, the findings of the aforementioned study should be applied to our study with caution. DDD-RVOT was chosen in our study because the RVOT is easily accessible from a surgical point of view and diaphragmatic muscle stimulation is less likely. At the time the study was designed, DDD-RVOT was regarded as an alternative pacing site that potentially produced less LV dysfunction than RV apical pacing through earlier Hisbundle activation. ${ }^{24}$ More recent data, including PV loop studies, suggest that none of the alternative pacing sites are superior to RV apical pacing. ${ }^{4,25,26}$

\section{Only Versus BIV Pacing}

The overall results for DDD-LV and DDD-BIV for systolic, diastolic, and dyssynchrony parameters were in the same range for both pacing modes. This finding is in line with previous data obtained by PV loop analysis in patients with severe LV dysfunction with and without left bundle branch block. ${ }^{5-7}$ Previous investigators have reported improved isovolumetric relaxation with DDD-BIV relative to DDD-LV in patients with heart failure and broad QRS; however, we did not observe any difference in the time constant of isovolumetric relaxation or $-\mathrm{dP} / \mathrm{dt}_{\max }{ }^{3}$ On the basis of our and previous data, LV-only pacing seems to be a suitable alternative for short-term postoperative pacing and may be the preferred option because of its simplicity.

\section{BIV Pacing Versus AAI}

No differences between AAI and DDD-BIV for systolic, diastolic, and dyssynchrony variables were determined. Although our patients did not have a wide QRS complex, a high degree of systolic dyssynchrony was observed, which was more pronounced toward the apex, a finding that has been reported previously in patients with heart failure undergoing long-term BIV pacing and cardiac surgical patients undergoing aneurysmectomy. ${ }^{8,27}$ Several echocardiographic studies have shown considerable intraventricular dyssynchrony despite normal QRS duration and have seen a positive response to BIV pacing when echocardiographic criteria of dyssynchrony are met. ${ }^{28,29}$ Although measures of systolic dyssynchrony were high in our patient population, considerable intraindividual differences in response could be found between DDD-BIV and AAI (Figure 5). Of the preoperative and intraoperative variables, only PQ duration during AAI at 90 beats/min predicted a superior response of DDD-BIV relative to AAI.

\section{Pacing Strategies After Coronary Artery Surgery}

DDD-BIV and DDD-LV are novel therapeutic options that can be achieved with standard epicardial pacing wires and standard external pacemakers. Placement of an additional LV pacing wire is achieved by luxation of the heart and replacement into the thoracic cavity, which takes less than 1 minute on average. ${ }^{12,14}$ The feasibility and safety of temporary BIV pacing, as well as the longevity of LV pacing wires, have been demonstrated in two studies. ${ }^{12,14}$ The average improvement in stroke work during DDD-BIV or DDDLV relative to DDD-RVOT was between $12 \%$ and $14 \%$ in 
our study, which has to be considered a relevant improvement in patients with severely reduced LV function.

On the basis of our findings, we suggest that patients with severely reduced LV function should receive an additional left-sided pacing wire. Pacing is mandatory if a higher grade $\mathrm{AV}$ block occurs. In this case, the recommended pacing mode in our patient population would be DDD-BIV or DDD-LV. When AV conduction is preserved and patients are in sinus bradycardia, pacing mode should be AAI unless a significant AV conduction delay occurs, in which case DDD-BIV or DDD-LV appears to be preferable on the basis of our data. The approximate threshold to switch from AAI to DDD-BIV or DDD-LV seems to be a 220-ms AV delay during atrial stimulation. Patients with an adequate sinus rate do not need any pacing at all; however, up to a sinus rate of 70 beats/min, an increase in the heart rate through pacing may be warranted to increase cardiac output as force-frequency relationships seem to be maintained, although this concept has to be validated in a larger set of patients. The ideal duration of postoperative pacing remains speculative. Recent results from our group suggest that prolonged postoperative pacing for 96 hours does not confer any clinical benefit. ${ }^{30} \mathrm{~A}$ practical suggestion might be to continue pacing as long as the patient is in need of inotropic support in the intensive care unit.

\section{Limitations}

Several limitations exist regarding the number of possible permutations in an invasive hemodynamic study with critically ill patients at the time of weaning from CPB. Pacing rate was kept constant at 90 beats/min, analogous to the studies to prevent postoperative atrial fibrillation. A lower base rate would have yielded a higher proportion of patients with spontaneous atrial depolarization and fluctuations in the spontaneous sinus rate, which would have made comparisons between different pacing modes difficult. Force-frequency relationships are known to be blunted for higher heart rates; however, this does not apply to BIV pacing according to a recent study. ${ }^{3}$ Pacing modes were tested for a relatively short period. After changing from one mode to the other, we observed instantaneous change in PV loops. A longer pacing period, which was not feasible because of the intraoperative setting, would have allowed an additional adaptation of the ventricle to the new electromechanical condition. Wire position was standardized, although variations of all three epicardial wire positions (left, right, and atrium) are theoretically possible. We aimed at investigating a homogeneous patient population with an ejection fraction lower than $35 \%$ from ischemic heart disease, with a QRS width less than $120 \mathrm{~ms}$, and without concomitant valve or aortic surgery. Whether our results can be transferred to cardiac surgical patients with reduced LV function not caused by ischemic heart disease or to patients with bundle branch block is an open question. Strictly speaking, our results only apply for the immediate postoperative period after weaning from CPB during the open-chest condition.

\section{CONCLUSIONS}

Temporary DDD-BIV or DDD-LV in patients with severely reduced $\mathrm{LV}$ function undergoing $\mathrm{CABG}$ is a novel therapeutic option that is hemodynamically superior to DDD-RVOT. Whether this therapy should be extended to a broader population in cardiac surgery needs further investigation.

\section{References}

1. Nalysnyk L, Fahrbach K, Reynolds MW, Zhao SZ, Ross S. Adverse events in coronary artery bypass graft (CABG) trials: a systematic review and analysis. Heart. 2003;89:767-72.

2. Bethea BT, Salazar JD, Grega MA, Doty JR, Fitton TP, Alejo DE, et al. Determin ing the utility of temporary pacing wires after coronary artery bypass surgery. Ann Thorac Surg. 2005;79:104-7.

3. Vollmann D, Luthje L, Schott P, Hasenfuss G, Unterberg-Buchwald C. Biventricular pacing improves the blunted force-frequency relation present during univentricular pacing in patients with heart failure and conduction delay. Circulation 2006;113:953-9.

4. Crystal E, Connolly SJ, Sleik K, Ginger TJ, Yusuf S. Interventions on prevention of postoperative atrial fibrillation in patients undergoing heart surgery: a metaanalysis. Circulation. 2002;106:75-80.

5. Lieberman R, Padeletti L, Schreuder J, Jackson K, Michelucci A, Colella A, et al Ventricular pacing lead location alters systemic hemodynamics and left ventricular function in patients with and without reduced ejection fraction. J Am Coll Cardiol. 2006;48:1634-41

6. Blanc JJ, Etienne Y, Gilard M, Mansourati J, Munier S, Boschat J, et al. Evaluation of different ventricular pacing sites in patients with severe heart failure: results of an acute hemodynamic study. Circulation. 1997;96:3273-7.

7. Kass DA, Chen CH, Curry C, Talbot M, Berger R, Fetics B, et al. Improved left ventricular mechanics from acute VDD pacing in patients with dilated cardiomyopathy and ventricular conduction delay. Circulation. 1999;99:1567-73.

8. Steendijk P, Tulner SA, Bax JJ, Oemrawsingh PV, Bleeker GB, van Erven L, et al. Hemodynamic effects of long-term cardiac resynchronization therapy: analysis by pressure-volume loops. Circulation. 2006;113:1295-304.

9. Foster AH, Gold MR, McLaughlin JS. Acute hemodynamic effects of atrio-biventricular pacing in humans. Ann Thorac Surg. 1995;59:294-300.

10. Weisse U, Isgro F, Werling C, Lehmann A, Saggau W. Impact of atrio-biventricular pacing to poor left-ventricular function after CABG. Thorac Cardiovasc Surg. 2002;50:131-5

11. Saxon LA, Kerwin WF, Cahalan MK, Kalman JM, Olgin JE, Foster E, et al. Acute effects of intraoperative multisite ventricular pacing on left ventricular function and activation/contraction sequence in patients with depressed ventricular function. J Cardiovasc Electrophysiol. 1998;9:13-21.

12. Dzemali O, Bakhtiary F, Dogan S, Wittlinger T, Moritz A, Kleine P. Perioperative biventricular pacing leads to improvement of hemodynamics in patients with reduced left-ventricular function-interim results. Pacing Clin Electrophysiol. 2006;29:1341-5

13. Steendijk P, Tulner SA, Schreuder JJ, Bax JJ, van Erven L, van der Wall EE, et al Quantification of left ventricular mechanical dyssynchrony by conductance catheter in heart failure patients. Am J Physiol Heart Circ Physiol. 2004;286:H723-30

14. Eberhardt F, Hanke T, Heringlake M, Massalme MS, Bechtel M, Misfeld M, et al. Feasibility of temporary biventricular pacing in patients with reduced left ventricular function after coronary artery bypass grafting. Pacing Clin Electrophysiol. 2007;30(Suppl. 1):S50-3.

15. Steendijk P, Staal E, Jukema JW, Baan J. Hypertonic saline method accurately determines parallel conductance for dual-field conductance catheter. Am J Physiol Heart Circ Physiol. 2001;281:H755-63.

16. Kelly RP, Ting CT, Yang TM, Liu CP, Maughan WL, Chang MS, et al. Effective arterial elastance as index of arterial vascular load in humans. Circulation. 1992; 86:513-21.

17. Nozawa T, Yasumura Y, Futaki S, Tanaka N, Uenishi M, Suga H. Efficiency of energy transfer from pressure-volume area to external mechanical work increases with contractile state and decreases with afterload in the left ventricle of the anesthetized closed-chest dog. Circulation. 1988;77:1116-24. 
18. Strickberger SA, Conti J, Daoud EG, Havranek E, Mehra MR, Pina IL, et al. Patient selection for cardiac resynchronization therapy: from the Council on Clinical Cardiology Subcommittee on Electrocardiography and Arrhythmias and the Quality of Care and Outcomes Research Interdisciplinary Working Group, in collaboration with the Heart Rhythm Society. Circulation. 2005;111:2146-50.

19. Auricchio A, Stellbrink C, Block M, Sack S, Vogt J, Bakker P, et al. Effect of pacing chamber and atrioventricular delay on acute systolic function of paced patients with congestive heart failure. The Pacing Therapies for Congestive Heart Failure Study Group. The Guidant Congestive Heart Failure Research Group. Circulation. 1999;99:2993-3001.

20. Breithardt OA, Stellbrink C, Kramer AP, Sinha AM, Franke A, Salo R, et al. Echocardiographic quantification of left ventricular asynchrony predicts an acute hemodynamic benefit of cardiac resynchronization therapy. J Am Coll Cardiol. 2002;40:536-45.

21. Sogaard P, Egeblad H, Pedersen AK, Kim WY, Kristensen BO, Hansen PS, et al. Sequential versus simultaneous biventricular resynchronization for severe heart failure: evaluation by tissue Doppler imaging. Circulation. 2002;106: 2078-84.

22. Nelson GS, Berger RD, Fetics BJ, Talbot M, Spinelli JC, Hare JM, et al. Left ventricular or biventricular pacing improves cardiac function at diminished energy cost in patients with dilated cardiomyopathy and left bundle-branch block. $\mathrm{Circu}$ lation. 2000;102:3053-9.

23. Bolli R. Myocardial 'stunning' in man. Circulation. 1992;86:1671-91.
24. Matsuoka K, Nishino M, Hashimoto A, Yamagami K, Tamai T, Kato H, et al. Right ventricular outflow tract pacing is superior to right ventricular apical pacing on cardiac diastolic function and synchronization-a study with color kinesis and tissue Doppler [abstract]. Circulation. 2006;114:II367.

25. Tse HF, Yu C, Wong KK, Tsang V, Leung YL, Ho WY, et al. Functional abnormalities in patients with permanent right ventricular pacing: the effect of sites of electrical stimulation. J Am Coll Cardiol. 2002;40:1451-8.

26. Padeletti L, Lieberman R, Schreuder J, Michelucci A, Collella A, Pieragnoli P, et al. Acute effects of His bundle pacing versus left ventricular and right ventricular pacing on left ventricular function. Am J Cardiol. 2007;100:1556-60.

27. Schreuder JJ, Castiglioni A, Maisano F, Steendijk P, Donelli A, Baan J, et al. Acute decrease of left ventricular mechanical dyssynchrony and improvement of contractile state and energy efficiency after left ventricular restoration. J Thorac Cardiovasc Surg. 2005;129:138-45.

28. Achilli A, Sassara M, Ficili S, Pontillo D, Achilli P, Alessi C, et al. Long-term effectiveness of cardiac resynchronization therapy in patients with refractory heart failure and "narrow" QRS. J Am Coll Cardiol. 2003;42:2117-24.

29. Yu CM, Lin H, Zhang Q, Sanderson JE. High prevalence of left ventricular systolic and diastolic asynchrony in patients with congestive heart failure and normal QRS duration. Heart. 2003;89:54-60.

30. Hanke T, Misfeld M, Heringlake M, Massalme M, Dyllus A, Wiegand U, et al. Biventricular pacing in patients with severely reduced LV-function after CABG-The BIVAC-Trial. Circulation. 2007;116:II681. 